\title{
Pharyngeal shape and dimensions in healthy subjects, snorers, and patients with obstructive sleep apnoea
}

Daniel O Rodenstein, Georges Dooms, Yves Thomas, Giuseppe Liistro, Dan C Stanescu, C Culée, Geneviève Aubert-Tulkens

\section{Methods}

SUBJECTS

We studied 17 men referred to our hospital with a complaint of heavy snoring and symptoms suggesting the sleep apnoea syndrome. They were studied by all night polysomnography and magnetic resonance imaging of the pharynx was performed. Only patients weighing less than $135 \mathrm{~kg}$ could be included in the magnetic resonance imaging study. Fifteen other apnoeic patients had to be excluded because claustrophobia or extreme anxiousness from being enclosed in the magnetic resonance imaging cylinder prevented their completing the study or because their inability to refrain from mouth breathing resulted in images with very poor edge definition.

In addition, eight healthy, non-obese young men, with no symptoms of sleep apnoea and known to be non-snorers, were studied by magnetic resonance imaging of the pharynx.

\section{SLEEP STUDIES}

All night polysomnography was performed ${ }^{7}$ and scored according to standard criteria. ${ }^{8}$ Episodes of apnoea were defined as complete cessation of airflow for 10 seconds or more.

Apnoea was classified as central, obstructive, or mixed according to presence of breathing efforts. Hypopnoea was defined as a greater than $50 \%$ decrease in oronasal flow lasting for at least 10 seconds. The sleep apnoea syndrome was defined by apnoeahypopnoea index (number of episodes of apnoea and hypopnoea per hour of sleep) of more than $15 .^{9}$ Movement arousals (expressed per hour of sleep, MA/h) were defined as any increase in electromyographic activity accompanied by alpha rhythm on the electroencephalograph for at least two seconds during a sleep epoch.

Pulmonary Division D O Rodenstein Y Thomas G Liistro

D C Stanescu

Radiology

Department

G Dooms

Electrophysiology

Laboratory

C Culée

G Aubert-Tulkens

Cliniques

Universitaires St Luc, Brussels, Belgium

Address for reprint requests: Dr D O Rodenstein, Service de Pneumologie, Cliniques St Luc, Av Hippocrate 10 1200 Bruxelles, Belgium. Accepted 11 July 1990
Despite the large number of studies devoted to pharyngeal characteristics in the sleep apnoea syndrome, no clear picture of these has yet emerged. The pharynx has been found to be small in some ${ }^{12}$ but not all ${ }^{3}$ studies, and pharyngeal compliance has been measured as lower than normal by some ${ }^{45}$ but not by others ${ }^{3}$; other possible but unproved factors are fat deposits around the pharynx ${ }^{126}$ and obesity influencing pharyngeal diameters. We therefore decided to re-examine the question, searching for a local factor contributing to airway closure in patients with sleep apnoea. We used magnetic resonance imaging, which avoids radiation exposure and yields both transverse and sagittal sections of the pharynx.

\section{MAGNETIC RESONANCE STUDIES}

Patients lay supine in the $2.5 \mathrm{~m}$ cylinder of a Phillips Gyroscan S15 apparatus. The head was maintained with Velcro straps in the neutral position, with the gaze perpendicular to the long body axis. The slice thickness was $5 \mathrm{~mm}$ and matrix size $256 \times 256$. First, a T1 weighted (TR $250 \mathrm{~ms}$, TE $30 \mathrm{~ms}$ ) coronal section was obtained to orient further images. A sagittal T1 weighted sequence (TR $450 \mathrm{~ms}$, TE $30 \mathrm{~ms}$ ) with seven slices was then obtained. The middle one (which was the only sagittal section used for analysis) passed through the central vertical plane of the pharynx, as determined from the coronal section. Thereafter, a transverse T1 weighted 
sequence (TR $450 \mathrm{~ms}$, TE $30 \mathrm{~ms}$ ) with six slices was obtained, perpendicular to the sagittal ones. The first section was obtained at the level of the hard palate and the last one at the level of the base of the epiglottis, with the four others equally spaced between them. Data acquisition lasted for about 10-12 minutes, the whole procedure taking 20-30 minutes. Throughout the study patients were asked to breathe quietly with the mouth closed. Special care was taken to keep patients awake, through frequent voice contact and close observation.

Magnetic resonance images were later projected and traced on paper. From these paper traces distances and surfaces were measured (see below). The procedure (paper tracing and measurements) was performed twice, at least one week apart, by the same observer, who was unaware of the polysomnographic results. Reproducibility was assessed by the paired $t$ test and the coefficient of variation of repeated measurements. The following measurements were made on the middle sagittal section (see fig 1); length of the soft palate, from the posterior nasal spine to the tip of the uvula; posterior airway space (the shortest horizontal distance between the posterior pharyngeal wall and the base of the tongue); shortest retropalatal diameter (the shortest horizontal distance between the posterior pharyngeal wall and the soft palate); sagittal area of the pharynx, from the nasopharynx (included) up to a horizontal line drawn through the base of the epiglottis; area of the soft palate; and available area-that is the difference between these two areas. From the transverse sections we measured the smallest transverse surface area (that is, the pharyngeal surface area of the section with the smallest pharyngeal surface) and the shortest transverse diameter of the pharynx. In addition, we computed, from all transverse sections of each subject, a mean anteroposterior:transverse $(\mathrm{AP} / \mathrm{T})$ diameter ratio: in each section the pharyngeal $\mathrm{AP}$ and $\mathrm{T}$ diameters were measured and their ratio was calculated. The average of all ratios constitutes the $\mathrm{AP} / \mathrm{T}$ diameter ratio. This is an index of cross sectional shape, a value of 1 corresponding to a circular shape. Surfaces were measured with a digital planimeter (Ottplan, A Ott, Kempten, West Germany). All magnitudes are expressed in linear dimensions, obtained with the magnification factor given by the magnetic resonance imaging system.

\section{STATISTICAL ASSESSMENT}

Differences in sleep data between snoring and apnoeic patients and in magnetic resonance imaging data between snorers, apnoeic patients, and healthy subjects were assessed by the Kruskal-Wallis analysis of variance. When significant differences were found comparisons between groups were performed with the Mann-Whitney test. Simple linear regressions were also performed.

\section{Results}

On the basis of the sleep data, seven patients were classified as simple snorers and 10 as apnoeic patients. The latter were heavier (in terms both of weight and of body mass index), the mean (SD) values being $78 \cdot 1(16 \cdot 1) \mathrm{kg}$ and $25.9(4.3) \mathrm{kg} / \mathrm{m}^{2}$ for snorers $v 92.2(16.3) \mathrm{kg}$ and $31.4(5.3) \mathrm{kg} / \mathrm{m}^{2}$ for apnoeic patients $(p<0.05)$. When compared with the healthy subjects, both groups of patients were older and heavier (mean age 27 (6), 40 (17), and 52 (10) years in normal, snoring, and apnoeic subjects; mean weight and body mass index of normal subjects $71.6(8.5) \mathrm{kg}$ and $21.8(2 \cdot 2)$ $\left.\mathrm{kg} / \mathrm{m}^{2} ; \mathrm{p}<0.05\right)$. Polysomnographic data are presented in table 1 . The total sleep time and the proportions of the different sleep stages did not differ between simple snorers and apnoeic patients. By contrast, not only the apnoea-
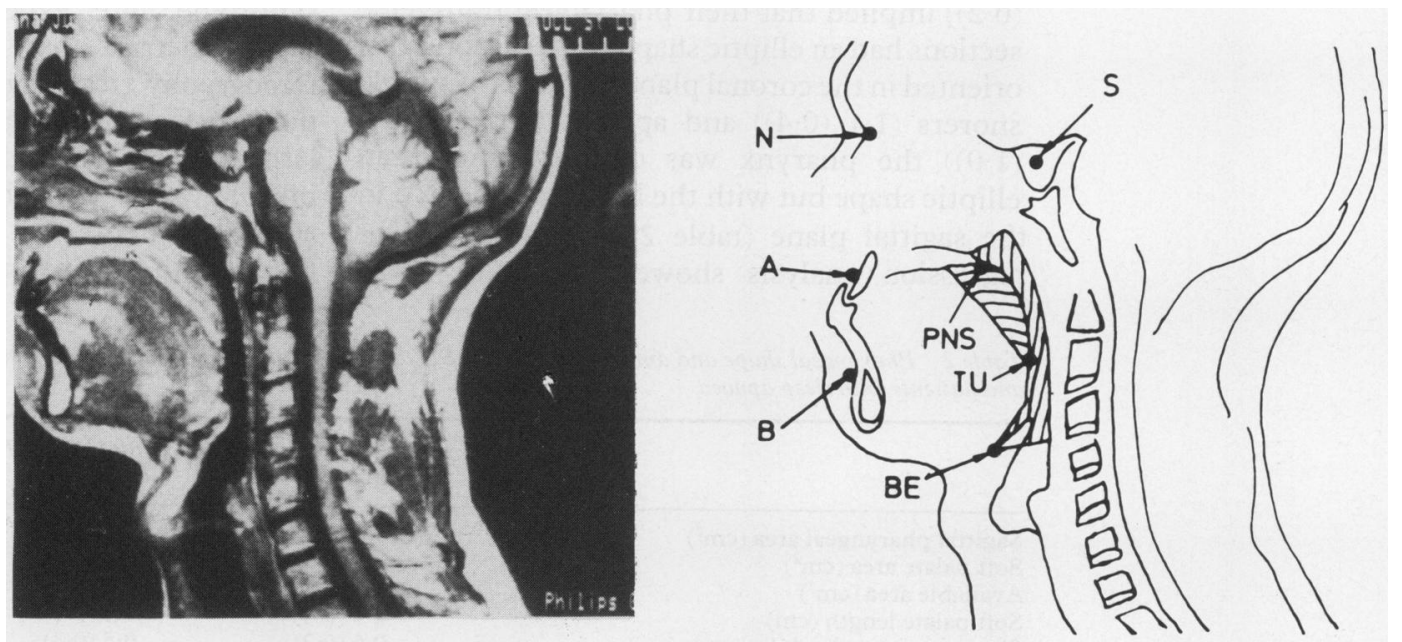

Figure 1 Midsagittal magnetic resonance images of the pharynx and related structures (left) and schematic representation with some anatomical landmarks (right). $N$-nasion; $S$-sella; $A$-subspinale; $B$-supramentale; $P N S$-posterior nasal spine; TU-tip of the uvula; BE-base of the epiglottis. The horizontal hatched area is the soft palate area and the vertical hatched area the available area; addition of these two gives the sagittal pharyngeal area. The shortest horizontal distance between the posterior pharyngeal wall and the base of the tongue, below the soft palate, is the posterior airway space. The shortest retropalatal diameter is the shortest horizontal distance between the posterior pharyngeal wall and the soft palate. 
Table 1 Sleep data (mean (SD)) in simple snorers and patients with sleep apnoea

\begin{tabular}{lcc}
\hline & $\begin{array}{l}\text { Simple snorers } \\
(n=7)\end{array}$ & $\begin{array}{l}\text { Sleep apnoea patients } \\
(n=10)\end{array}$ \\
\hline TST (min) & $414(99)$ & $432(92)$ \\
Stages 1-2, non-REM (\% TST) & $56 \cdot 2(19 \cdot 7)$ & $60 \cdot 9(9 \cdot 6)$ \\
Stages 3-4, non-REM (\% TST) & $27 \cdot 3(17 \cdot 3)$ & $20 \cdot 2(10 \cdot 9)$ \\
Stage REM (\% TST) & $16 \cdot 5(5 \cdot 2)$ & $18 \cdot 8(5 \cdot 7)$ \\
Lowest SaO $(\%)$ & $88 \cdot 7(3 \cdot 6)$ & $72 \cdot 3(12 \cdot 7)^{\star}$ \\
AHI & $6 \cdot 7(4 \cdot 6)$ & $56 \cdot 3(41 \cdot 7)^{\star}$ \\
MA/h & $13 \cdot 1(14 \cdot 9)$ & $66 \cdot 2(33 \cdot 5)^{\star}$ \\
\hline
\end{tabular}

$\star$ Sleep apnoea $v$ snoring: $\mathrm{p}<0.05$.

TST-total sleep time; $\mathrm{SaO}_{2}$-arterial oxygen saturation; $\mathrm{AHI}$-apnoea-hypopnoea index; $\mathrm{MA} / \mathrm{h}-$ movement arousals per hour.

hypopnoea index (by definition) but also the movement arousal measure $(\mathrm{MA} / \mathrm{h})$ were significantly higher and the lowest arterial oxygen saturation $\left(\mathrm{SaO}_{2}\right)$ significantly lower in the apnoeic patients (table 1 ). More than $80 \%$ of all episodes of apnoea were of the obstructive or mixed type in both groups.

The analysis of magnetic resonance images of the pharynx showed that there was no significant difference between the two sets of paper tracings for any of the measurements. The coefficient of variation for all measurements for the two sets of paper tracings ranged from zero to $33^{\circ}$, with a mean value of $14.3 \%$.

The sagittal pharyngeal area on the magnetic resonance image was larger in apnoeic patients than in simple snorers, whereas the soft palate area was significantly larger in apnoeic patients than in normal subjects (table 2). The available area, however, was similar in the three groups. The posterior airway space and the shortest retropalatal diameter were also similar in the three groups. On the transverse sections there was no significant difference between the groups in the smallest transverse surface area, whereas the shortest transverse diameter was significantly smaller in apnoeic patients than in healthy subjects (table 2 ). The AP/T diameter ratio was significantly smaller in healthy subjects than in simple snorers or apnoeic patients (fig 2). The mean (SD) value of the $\mathrm{AP} / \mathrm{T}$ diameter ratio in healthy subjects $(0.4$ $(0 \cdot 2))$ implied that their pharyngeal transverse sections had an elliptic shape, with the long axis oriented in the coronal plane, whereas in simple snorers $(1 \cdot 1(0.4))$ and apnoeic patients (1.6 $(1 \cdot 0))$ the pharynx was circular or had an elliptic shape but with the long axis oriented in the sagittal plane (table 2, figs 3-5). Linear regression analysis showed that the $\mathrm{AP} / \mathrm{T}$

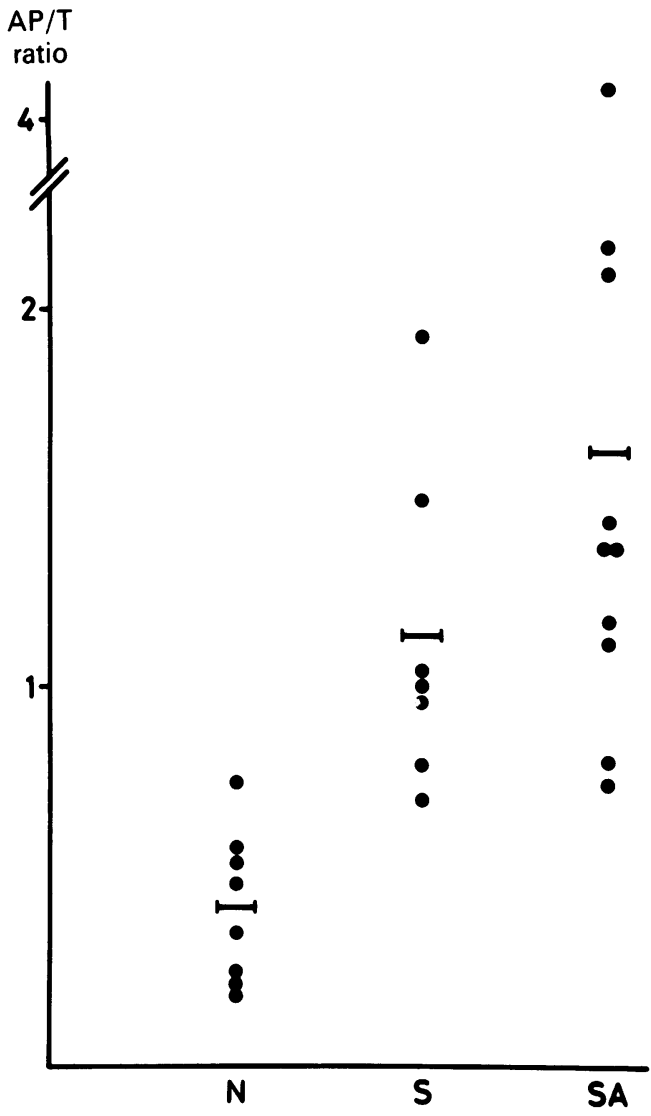

Figure 2 Anteroposterior:transverse $(A P / T)$ diameter ratio of the pharynx in normal subjects $(N)$, snoring patients $(S)$, and patients with the sleep apnoea syndrome $(S A)$. Each point is the mean $A P / T$ ratio for one individual. Bars indicate mean group values.

diameter ratio was unrelated to the weight $(r=0.26)$, the body mass index $(r=0.15)$ or the age $(r=0.03)(p>0.1$ in each case), whereas it was related to the apnoea-hypopnoea index $(\mathrm{r}=0.55, \mathrm{p}<0.05)$.

\section{Discussion}

We have studied a control group of young healthy subjects and a heterogenous group of patients who snored or had the sleep apnoea syndrome. We expected, on the basis of cephalometric (that is, sagittal), computed tomography (transverse), and acoustic reflection (surface area) studies, ${ }^{124510}$ to find rather large differences in the magnetic resonance imaging data on pharyngeal size between apnoeic patients and simple snorers and between both groups and healthy subjects. We

Table 2 Pharyngeal shape and dimensions (mean (SD)) from magnetic resonance imaging in normal subjects, simple snorers, and patients with sleep apnoea

\begin{tabular}{|c|c|c|c|}
\hline & $\begin{array}{l}\text { Normal subjects } \\
(n=8)\end{array}$ & $\begin{array}{l}\text { Simple snorers } \\
(n=7)\end{array}$ & $\begin{array}{l}\text { Sleep apnoea patients } \\
(n=10)\end{array}$ \\
\hline Sagittal pharyngeal area $\left(\mathrm{cm}^{2}\right)$ & $15 \cdot 4(1 \cdot 0)$ & $14 \cdot 2(2 \cdot 9)^{\star}$ & $17 \cdot 4(2 \cdot 0)$ \\
\hline Soft palate area $\left(\mathrm{cm}^{2}\right)$ & $3.7(0.5)$ & $4.8(1 \cdot 2)$ & $5 \cdot 6(1 \cdot 3) \dagger$ \\
\hline Available area $\left(\mathrm{cm}^{2}\right)$ & $11 \cdot 7(1 \cdot 1)$ & $9 \cdot 4(2 \cdot 0)$ & $11 \cdot 8(1 \cdot 7)$ \\
\hline Soft palate length $(\mathrm{cm})$ & $4 \cdot 1(0 \cdot 4)$ & $4 \cdot 5(1 \cdot 1)$ & $4 \cdot 7(0 \cdot 7)$ \\
\hline Shortest retropalatal diameter $(\mathrm{cm})$ & $0.6(0 \cdot 2)$ & $0.5(0.3)$ & $0 \cdot 4(0 \cdot 1)$ \\
\hline Posterior airway space $(\mathrm{cm})$ & $0.8(0.3)$ & $0.9(0.5)$ & $1.3(0.5)$ \\
\hline Smallest transverse surface area $\left(\mathrm{cm}^{2}\right)$ & $1 \cdot 2(0.4)$ & $1.5(0.6)$ & $1.6(0.5)$ \\
\hline Shortest transverse diameter $(\mathrm{cm})$ & $1.7(0.5)$ & $1.4(0.5)$ & $1.0(0.4) \dagger$ \\
\hline $\mathrm{AP} / \mathrm{T}$ diameter ratio & $0.4(0.2)$ & $1 \cdot 1(0 \cdot 4) \ddagger$ & $1.6(1.0) \dagger$ \\
\hline
\end{tabular}

$\star$ Snoring $v$ sleep apnoea; †sleep apnoea $v$ normal; $\ddagger$ snoring $v$ normal: $\mathrm{p}<0.05$ in each case.

AP $/ \mathrm{T}$ - anteroposterior:transverse. 


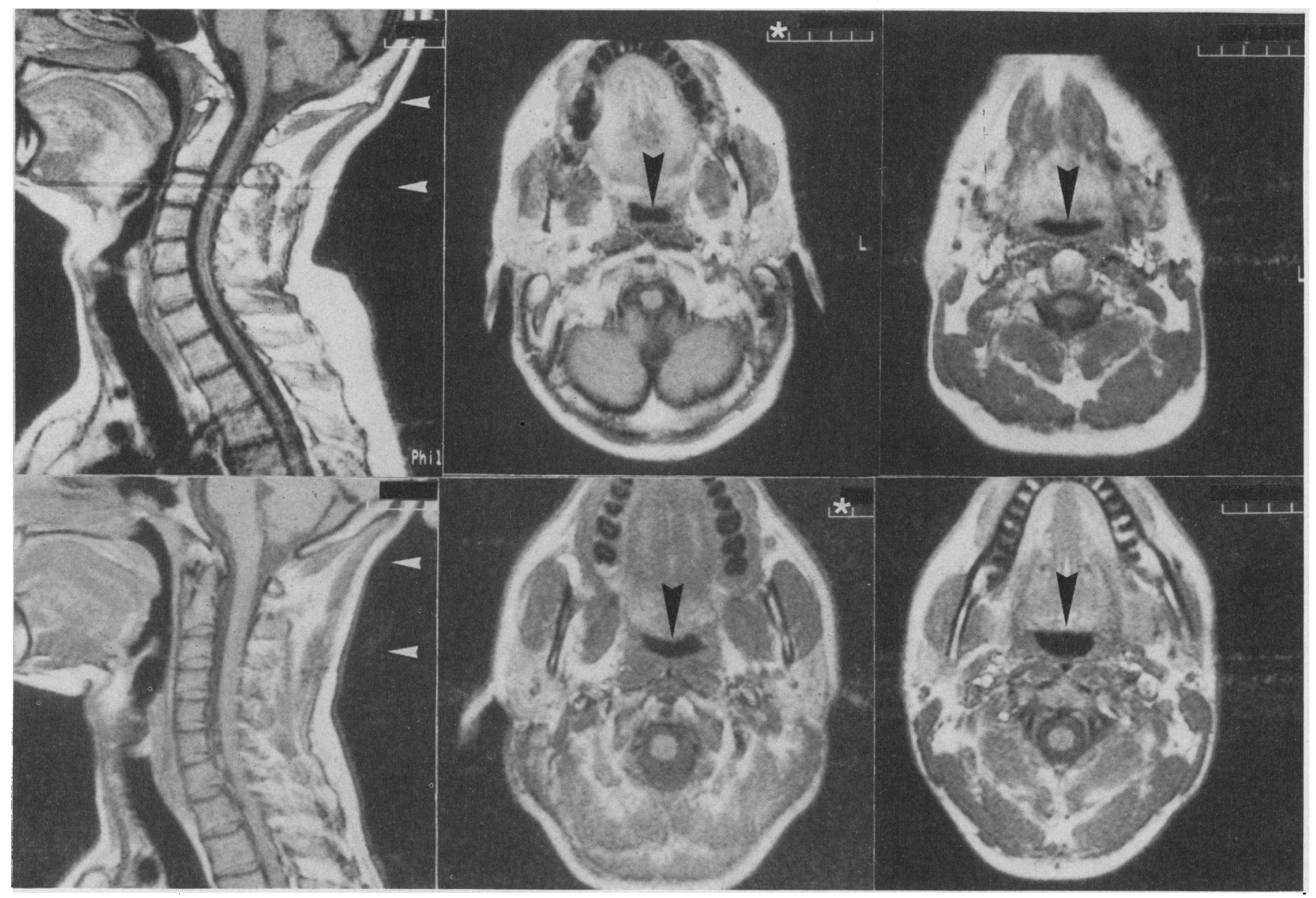

Figure 3 Magnetic resonance images of the pharynx in two normal subjects. The left photographs show the sagittal section. White arrowheads indicate the level of the transverse sections shown in the centre (higher level) and right (lower level) photographs, where the arrowhead indicates the pharynx. The magnification factor is the same for all the images. The asterisk in the scale bar indicates $1 \mathrm{~cm}$.

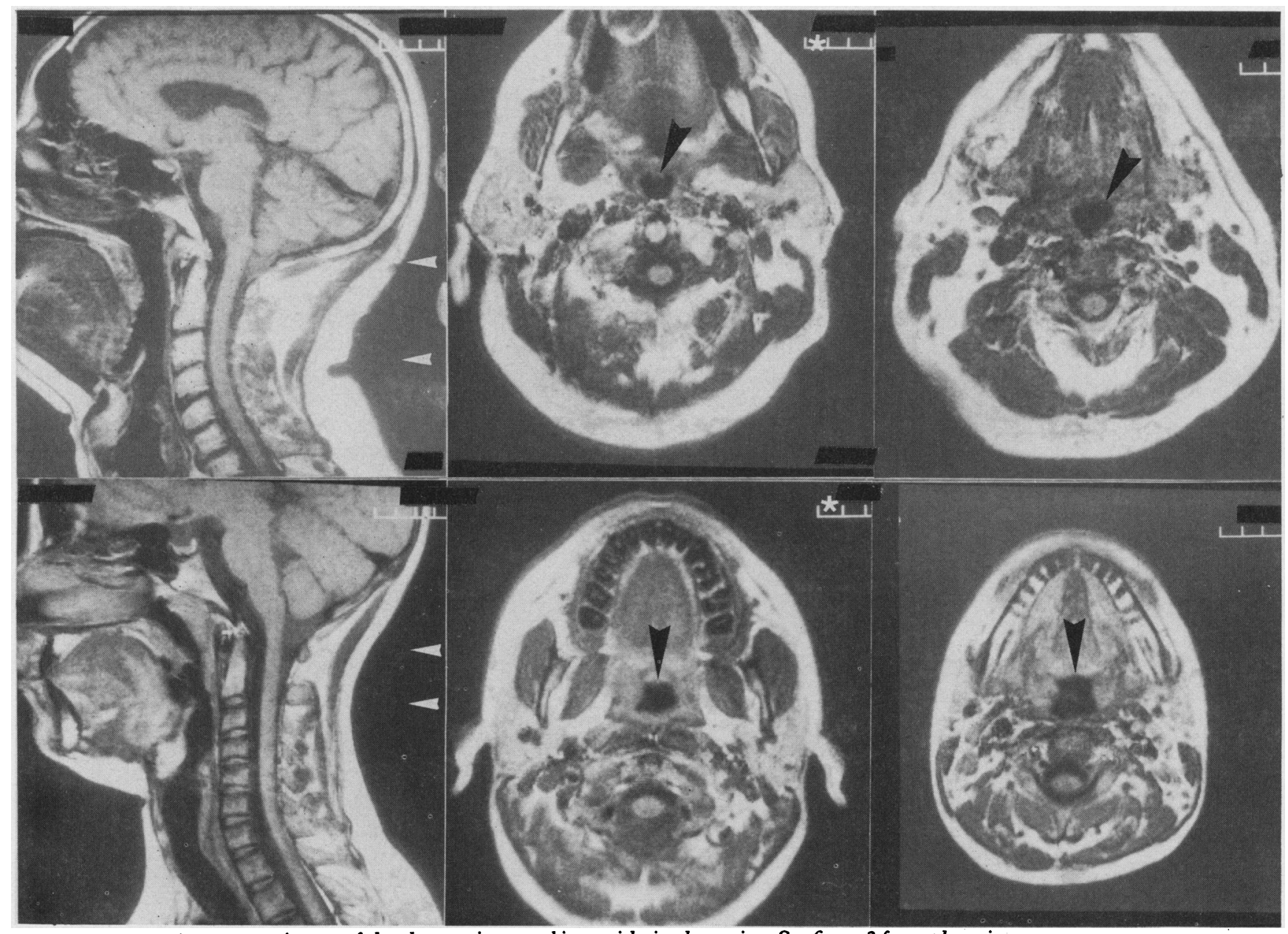

Figure 4 Magnetic resonance images of the pharynx in two subjects with simple snoring. See figure 3 for explanations. 


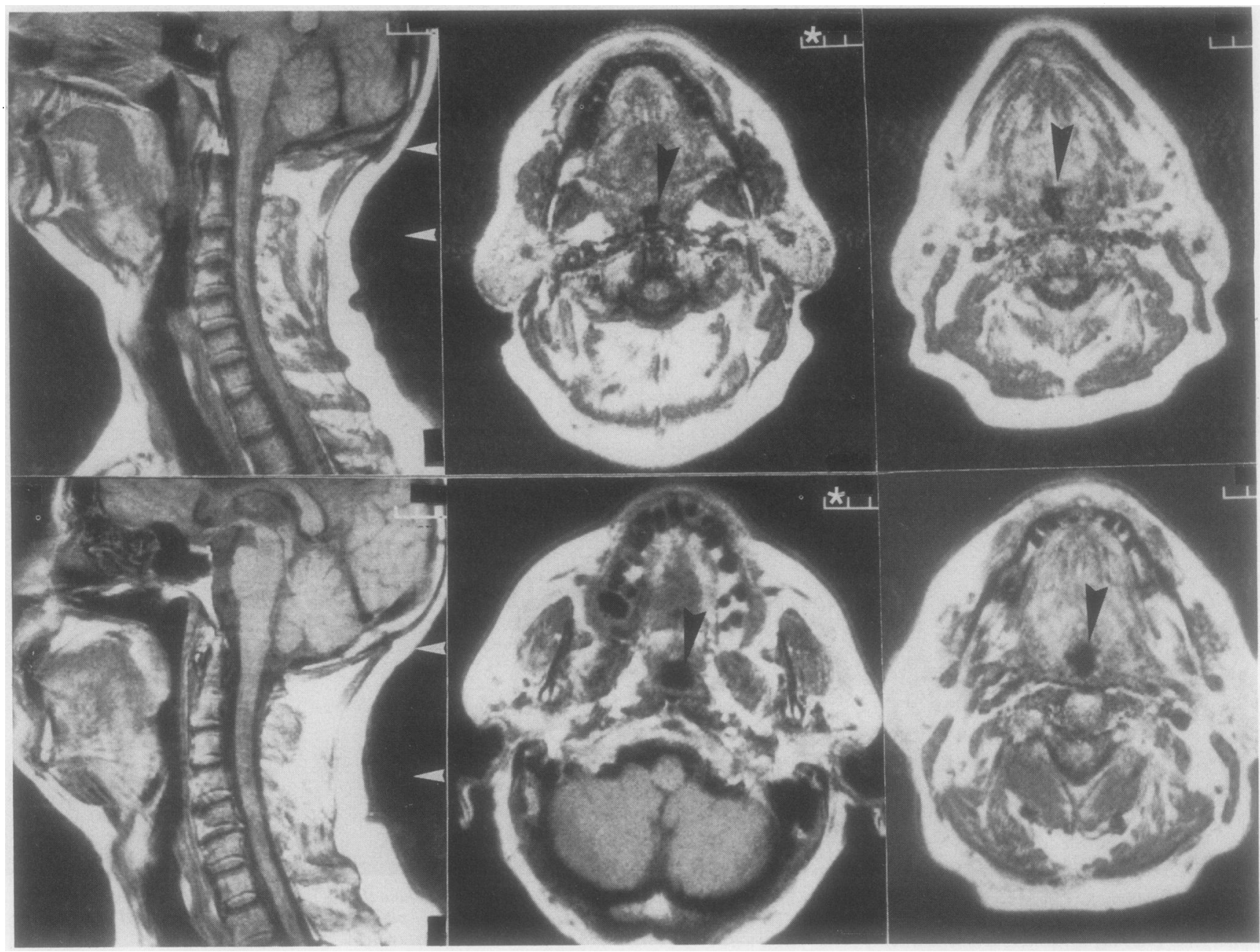

Figure 5 Magnetic resonance images of the pharynx in two patients with the sleep apnoea syndrome. See figure 3 for explanations.

found, by contrast, rather small differences (or no difference at all) in most magnetic resonance imaging measurements. This discrepancy with respect to previous results could be due to several factors, including body position (sitting in cephalometric studies, supine here), duration of the studies (much longer for magnetic resonance imaging than for radiography), quiet breathing (this study) versus apnoea (cephalometry or computed tomography), nose versus mouth (as in acoustic reflection studies) breathing, or the lesser severity of the disease in our patients than in most of those previously studied. We would emphasise, however, that others have reported rather normal pharyngeal diameters and cross sectional areas in apnoeic patients, ${ }^{36}$ in contrast also to the findings of previous studies.

The only magnetic resonance measurement that proved to differ between healthy controls and both snoring and apnoeic patients was the pharyngeal shape factor-that is, the AP/T diameter ratio (fig 2). This shape difference was due not to a difference in the AP diameter but to a reduction in the transverse diameter in simple snorers and apnoeic patients (though this was significant only in the latter). Thus in healthy controls the pharynx is elliptic with the long axis oriented in the coronal plane, whereas in the snorers and apnoeic patients it is either circular or elliptic but with the long axis oriented in the sagittal plane (figs 3-5). To our knowledge, the shape of the transverse section of the pharynx has never been analysed, though Kuna $e t a l^{3}$ stated that they did not find any systematic difference in shape on visual inspection of computed tomography sections of the pharynx of healthy subjects and apnoeic patients. Nevertheless, the pharyngeal shape in normal transverse sections of the neck in textbooks of computed tomography and magnetic resonance imaging ${ }^{11-15}$ is indeed elliptical, with the long axis oriented in the coronal plane (see also the cover figures in the January-April 1989 issues of the Journal of Applied Physiology, showing three dimensional reconstruction of the pharyngeal lumen). Moreover, in the few papers reporting on the computed tomographic features of the pharyngeal airway in sleep apnoea the sections from normal subjects (shown for comparison) also show elliptic shapes, ${ }^{12}$ as in our healthy subjects. In a recently published paper obese non-apnoeic subjects had elliptic cross sectional pharyngeal shapes (with the long axis oriented in the coronal plane), whereas obese apnoeic subjects showed rather circular shapes (see figs 3, 4, and 7 in ref 6). Whether the decrease in the transverse diameter of the pharynx is due to fat deposits, preferentially located lateral to the 
pharyngeal lumen, ${ }^{6}$ or to other structural factors cannot be inferred from our data.

Our control group was not matched for age or weight with snoring or apnoeic patients. Although the shape factor of the pharynx was not correlated with either weight, body mass index, or age, our results should await further confirmation. Nevertheless, our findings make sense in pathophysiological terms, as suggested by the significant correlation between the AP/ $T$ diameter ratio and the apnoea-hypopnoea index. If for any structural reason the transverse diameter of a pharynx became smaller, as in our patients, this would result in a decrease in pharyngeal cross sectional area. To keep cross sectional area normal, the main pharyngeal dilators (genioglossus and geniohyoid) need to augment their activity and, by pulling the tongue forward, increase the anteroposterior diameter of the pharynx. This would result, during wakefulness, in a normal cross sectional area and in a circular or anteroposterior elliptic shape in the transverse section. During sleep, however, as the main dilators decrease their activity, the pharyngeal cross sectional area would decrease below normal, and partial closure (in snoring) or complete closure (in apnoea) would ensue. As the shape factor (AP/T diameter ratio) is unrelated to the body mass index, this could explain why many lean people develop the sleep apnoea syndrome, and why not all obese people do so.

In conclusion, we have found a shape difference between the pharyngeal airway of snorers and patients with sleep apnoea and that of healthy subjects. This shape difference may play a part in the mechanism of sleep related disordered breathing.
This work was supported in part by grant 9.452887 from the Belgian Fonds de la Reserche Scientifique Médicale and by a grant from NV Phillips Petroleum Chemicals Belgium. We gratefully acknowledge all subjects who participated in the study; Mrs M Dury and V Franche for skilful technical help; and Mrs V Franche for typing the manuscript.

1 Haponik EF, Smith PL, Bohlman ME, Allen RP, Goldman SM, Bleecker ER. Computerized tomography in obstructive sleep apnea. Am Rev Respir Dis 1983; 127:221-6.

2 Suratt PM, Dee R, Atkinson RL, Armstrong P, Wilhoit SC. Fluoroscopic and computed tomographic features of the pharyngeal airway in obstructive sleep apnea. Am Rev pharyngeal airway in obstru
Respir Dis 1983;127:487-92.

3 Kuna ST, Bedi DG, Ryckman C. Effect of nasal airway positive pressure on upper airway size and configuration. Am Rev Respir Dis 1988;138:969-975.

4 Bradley TD, Brown IG, Grossman RF, et al. Pharyngeal size in snorers, nonsnorers and patients with obstructive sleep apnea. N Engl J Med 1986;315:1327-31.

5 Brown IB, McClean PA, Boucher R, Zamel N, Hoffstein V. Changes in pharyngeal cross-sectional area with posture and application of continuous positive airway pressure in patients with obstructive sleep apnea. Am Rev Respir Dis 1987;136:628-32.

6 Horner RL, Mohiaddin RH, Lowell DG, et al. Sites and sizes of fat deposits around the pharynx in obese patients with obstructive sleep apnea and weight matched controls. Eur Respir J 1989;2:613-22.

7 Aubert-Tulkens G, Hamoir M, Van den Eeckhaut J, Rodenstein DO. Failure of tonsil and nose surgery in adults with severe sleep apnea of long standing severe sleep apnea severe sleep apnea of long standing severe sleep
syndrome. Arch Intern Med 1989;149:2118-21.

8 Rechtschaffen A, Kales A. A manual of standardized terminology, techniques and scoring system for sleep stages of human subjects. Los Angeles: University of California at Los Angeles, 1968.

9 Gould GA, Whyte KF, Rhind GB, et al. The sleep hypopnea syndrome. Am Rev Respir Dis 1988;137:895-8.

10 Jamieson A, Guilleminault C, Partinen M, Quera-Salva MA. Obstructive sleep apneic patients have craniomandibular abnormalities. Sleep 1986;9:469-77.

11 Gambarelli J, Guérinel G, Chevrot L, Mattei M. Computerized axial tomography. Berlin: Springer, 1977.

12 Barreau J, Pringot J, Buben JY, Bodart P. Anatomical interpretation of computed tomography. Namur, Belgium: Presses universitaires de Namur, 1982.

13 Wegener $\mathrm{OH}$. Whole body computerized tomography. Berlin: Shering, 1983.

14 Mc Grath P, Mills P. Atlas of sectional anatomy. Basel: Karger, 1984

15 Daniels DC, Haughton VM, Naidich TP. Cranial and spinal magnetic resonance imaging. An atlas and guide. New York: Raven Press, 1987. 